\title{
ASSISTINDO COM TRADUÇÃO: ENCENAÇÃO E A RECEPÇÃO DE LEGENDAS ELETRÔNICAS *
}

\author{
P. A. Skantze
}

Elas surgiram na década de 1980 com a ópera. As pequenas letras líquidas em geral amarelas - apareciam em uma caixa preta retangular suspensa bem acima do palco, com sua pequena tela preta estranhamente apoiada no alto da cortina. $\mathrm{O}$ cantor entrava, abria a boca e "cinque, dieci, venti, trente, trentesei, quarantatre" era o que se escutava, mas de súbito a caixa ganhava vida e os números iam aparecendo, esclarecedores: “5, 10, 20, 30, 36, 43”.

As opiniões divergiram. Os aficionados da ópera acharam irritante e de mau gosto um texto, colocado no proscênio, invadindo a cena original dos cantores. Os que argumentavam que a tradução tornaria a ópera mais acessível a um público não familiarizado com o repertório consideraram que a pequena caixa preta era mais um auxílio do que uma interferência. ${ }^{1}$

Desde essas primeiras experiências, a utilização da tradução simultânea na ópera e no teatro tem aumentado, particularmente em festivais europeus de teatro internacional. Se, por exemplo, uma companhia holandesa traz uma peça de Christopher Marlowe para um festival francês, o processo tradutório continua após a primeira tradução do inglês para o holandês, com a tradução holandesa sendo vertida para legendas em francês de modo a que o público do festival compreenda o que está se passando no palco.

A primeira diferença para o espectador ao assistir a uma peça com legendas anuncia-se fisicamente pela necessidade de desviar o olhar da ação que ocorre no palco para as palavras que vão surgindo e vice-versa. Uma mulher entra, fecha a porta, vai

\footnotetext{
*Embora no título apareça a expressão "legendas eletrônicas" como tradução do termo surtitles, ao longo do texto em português optou-se por usar apenas "legenda(s)" com vistas a uma maior leveza da tradução.

${ }^{1}$ As primeiras legendas eram projetadas por meio de um "projetor de slides sequencial", e novos slides tinham que ser preparados para cada produção (ver Sisk, 1986). Agora, a maioria dos teatros e óperas utiliza um sistema de texto gerado por computador que proporciona a flexibilidade de se fazerem alterações e de se controlar o tempo de modo bem simples. Ver Poole (1987) para uma descrição da reação crítica às primeiras legendas. A maior parte do que foi escrito até o momento sobre a legendagem eletrônica encontra-se em críticas de ópera.
} 
para a cozinha e começa a quebrar ovos; ela emite sons para acompanhar a ação, até que um homem se aproxima e diz: "Hey there, Stella baby" ("Oi, Stella querida"). Agora, embora a mulher continue o que estava fazendo e o homem se volte em sua direção, os espectadores deixam de olhar para a cena e erguem a vista rapidamente de modo a poderem ler: "Ciao, Stella mia cara". Assim, o movimento do olhar do espectador provoca como que um aceno de cabeça contínuo, levantando-a para ver as palavras e abaixando-a para ver o palco. Paralelamente à mudança constante do olhar do palco para o texto há a recepção auditiva, pois o espectador continua a escutar as palavras ditas enquanto lê o que significam.

O timing adquire um novo sentido no mundo da tradução simultânea. Um espectador pode, por exemplo, ir a um espetáculo em sua própria língua, ignorando as legendas e apenas assistindo à encenação, e de repente ser surpreendido por risadas no teatro, três segundos antes de o ator chegar ao fim de uma piada. Os "espectadoresleitores" apreendem a fala de uma só vez. Embora o responsável pelas legendas possa tentar seguir o fluxo das partes de cada fala, pelo menos duas ou três linhas do diálogo aparecem ao mesmo tempo, resultando que o significado, para quem assiste com tradução, é dado pela leitura da legenda, antes da apreensão da cena. ${ }^{2}$

Além disso, o ritmo da tradução que aparece acima do palco varia de acordo com o método. Eu já vi muitas peças em que as legendas "vinham atrás" da ação e de repente era preciso ler bem rápido, em geral muito rápido para que se conseguisse ler realmente todas as linhas. Nessa situação, suspiros de frustração podem ser ouvidos na plateia; toma-se consciência da natureza compartilhada da tarefa de compreender a ação não só a partir do que se vê, como também do que se lê. Assim como a incompreensão pode ser ouvida no teatro, uma compreensão incompleta também pode.

Na noite de estreia de uma encenação em 2001 de As criadas, de Jean Genet, apresentada em francês no Teatro Valle, em Roma, houve falta de energia elétrica por três vezes. Durante não menos que dez minutos a caixa das legendas ficou apagada, enquanto os atores, na penumbra, continuaram a representar. Ao longo de uma ou duas horas de espetáculo torna-se um hábito a leitura das legendas, a representação de um papel na decifração de significado. Isso fica claríssimo quando o hábito é rompido, como ocorreu naquela noite. Como se a "ocupação do espectador tivesse acabado",

\footnotetext{
2 As legendas para ópera desfrutam de um tempo maior do que as legendas de peças teatrais; as linhas da legenda são com frequência repetidas ou então o tempo necessário para lê-las é muito menor do que o necessário para cantá-las, de modo que a plateia pode erguer a vista, compreender e depois voltar a assistir ao que se passa no palco.
} 
tinha-se a impressão de um silêncio um tanto confuso, estupefato, enquanto os espectadores-leitores esperavam para obter novamente as ferramentas de sua atividade. Enquanto os críticos de ópera queixavam-se das legendas porque elas podiam encorajar a preguiça no público, que não precisaria mais dedicar-se à leitura e à compreensão do libreto, no momento da encenação um tipo de trabalho diferente é realizado pelo espectador que lê.

Em teoria, o método de legendagem deixa a escolha por conta do espectador. Mesmo que a língua do espetáculo seja incompreensível, o espectador pode optar por ignorar a legenda. A facilidade com que se pode ignorar a legenda depende de onde se está sentado no teatro. Se pensarmos em um teatro relativamente tradicional, os lugares mais caros da plateia, ironicamente, exigem que o espectador realize um esforço maior no movimento de olhar para cima e para baixo. O balcão e a galeria costumam estar na mesma altura da legenda. Para os que estão nos lugares mais altos é mais difícil ignorar as palavras escritas. Será que recusar a "ajuda" da legenda faz com que a recepção da encenação em curso seja mais "autêntica"? Trata-se de uma questão fascinante, senão impossível de ser respondida, uma vez que se pode argumentar, por um lado, que o significado "verdadeiro" está na atuação e nos gestos e não na compreensão do texto; por outro lado, os atores talvez digam que trabalham para comunicar através da língua e que o espectador que não compreende o eles dizem não está vendo a peça.

É claro que esses possíveis modelos de recepção fazem aflorar velhas questões acerca da tradução: fidelidade, tradução exata, versão coloquial, autenticidade. Por exemplo, uma produção de uma peça de Shakespeare em russo talvez utilize uma tradução de Boris Pasternak modificada pelo diretor. Quando a peça é encenada em um festival na Itália, as legendas muitas vezes não traduzem "o que está sendo dito", porque os legendadores usam uma versão italiana padrão, como a de Giorgio Melchiori para o Rei Lear. Assim, o público recebe a "essência": quando Cordélia lamenta "I cannot heave my heart into my mouth" [literalmente, "não sou capaz de trazer meu coração para a boca"], o público lê "non risco a sollevare il peso del mio amore fino alle mie labbra" ("I cannot lift the weight of my love up to my lips" [literalmente, "não consigo elevar o peso de meu amor a meus lábios"]) enquanto os atores falam uma versão russa diferente (Shakespeare, 1976, p. 13).

A maior parte da plateia não terá consciência da dissonância, a não ser que domine diversas línguas e conheça de cor o texto original. Na encenação, mesmo quando um espectador lê, a tradução nunca consiste apenas em palavras; sempre há as 
informações físicas dos atores em seu gestual, na entonação, no silêncio que cria um padrão de troca no qual a leitura que busca significado - mesmo a suspeita de que as palavras lidas não são necessariamente as palavras que estão sendo ditas — é intercalada pela interpretação que brota do que se vê. Mais uma consequência das legendas é aumentar a consciência de que uma peça é um texto escrito.

Consideremos a produção de Peter Sellars de 2000, A história de um soldado. Quando encenada no Teatro Índia, em Roma, a sessão iniciou-se com a leitura de um longo poema de Gloria Enedina Alvarez pela própria autora - a quem Sellars havia encarregado de escrever uma versão moderna do libreto para a composição de Stravinski que fosse ambientada na parte oriental de Los Angeles. Enquanto Alvarez recitava/lia seu poema, uma mulher próxima a ela lia simultaneamente uma tradução italiana. Como o poema continha trechos em espanhol, as duas versões pareciam convergir de vez em quando, por efeito das semelhanças entre o italiano e o espanhol, duas línguas neolatinas. Quando o público foi conduzido ao espaço destinado à encenação do musical, via-se o palco e, à esquerda deste, uma cadeira e uma mesa com um computador Macintosh. No alto, apareciam as conhecidas letras amarelas da legenda eletrônica; na lateral do palco, a pessoa que as manipulava parecia o mágico de $\mathrm{Oz}$ quando as cortinas se abriram. ${ }^{3}$ Mas a percepção do texto por parte dos espectadores nessa noite operística veio da inserção da poesia em tradução, do destaque dado à figura da autora do libreto e da exposição dos mecanismos da legendagem eletrônica.

No caso de óperas, pode-se argumentar que os espectadores nem sempre têm consciência do texto, uma vez que este é alongado e embelezado pelas notas da música. Mesmo para falantes nativos de inglês, as óperas de Benjamin Britten, só para dar um exemplo, talvez contenham passagens incompreensíveis devido ao modo como são cantadas, ou à junção de palavras em uma ária. Com a legenda na parte superior do palco, as palavras aparecem "intactas" antes das notas mudarem a cadência e os tempos. Um momento de troca transcultural e transtextual na produção de Sellars ocorreu com a escolha dos tradutores italianos de manter a expressão Yo bro em inglês, presumindo que esta fosse transmutável entre os públicos e compreensível devido ao uso cotidiano.

\footnotetext{
${ }^{3}$ Embora a "máquina" de legendas tenha se tornado parte da apresentação nessa produção, pareceu claro que isso não foi uma intervenção deliberada do diretor. O Teatro Índia havia sido restaurado no lugar de uma antiga fábrica de sabão, e, quando a produção de Sellars foi encenada, o espaço não tinha uma área que pudesse esconder a parte técnica.
} 
Nesse caso, a pressuposição do entendimento por parte da plateia sem dúvida tem relação direta com a onipresença das músicas e filmes americanos contemporâneos na Itália.

Embora muitos inventores e fabricantes valorizem a facilidade prometida pelas novas tecnologias, a maioria das pessoas já sabe como essas novas tecnologias vêm acompanhadas de suas formas próprias de ansiedade. Com a legendagem eletrônica não é diferente; se o espectador está lendo em um idioma que conhece bem mas que não é a sua língua materna, a leitura e a compreensão podem ser subitamente interrompidas quando aparece uma palavra desconhecida ou que não consegue identificar naquele momento. Alguns minutos se passam no processo de tentar lembrar qual é o significado daquela palavra a fim de entender "o que está acontecendo", e ao longo desses minutos a legenda e a peça seguem em frente. Talvez alguns espectadores simplesmente não consigam ler rápido o suficiente para acompanhar as linhas; e às vezes a ansiedade surge a partir do processo errático da própria legenda, deixando o espectador inseguro acerca da relação entre as palavras na tela e o que está sendo dito no palco.

Assim como - acredita-se — os demais sentidos são aguçados quando se perde a visão, os sentidos do espectador cuja compreensão é mediada pela legenda eletrônica sofrem o mesmo processo. O ritmo torna-se uma parte incrivelmente importante da encenação. Uma língua desconhecida ouvida por duas horas torna-se paradoxalmente familiar em seus ritmos, suas repetições, suas exclamações. Quando a companhia de Christoph Marthaler, de Zurique, encenou Noite de reis em alemão em Roma (novembro de 2001), o teatro usou nas legendas uma tradução italiana padrão de Shakespeare. No entanto, em alguns momentos da encenação, um personagem, secundário se não fosse por essa intervenção, vinha ao proscênio e falava. Durante sua fala, não havia legenda. Na terceira vez em que ele fez isso, percebi que recitava um soneto; não que eu estivesse compreendendo as palavras, ou que tivesse lido o programa, mas simplesmente porque a cadência da língua e o fato de que se tratava de uma peça de Shakespeare deram-me a pista para identificar esses monólogos misteriosos, mas que apresentavam uma métrica. (Pode-se argumentar que o meu reconhecimento auditivo tenha sido possível devido ao lirismo da tradução alemã dos sonetos feita pelo poeta Paul Celan.)

Em dezembro de 1999, o Teatro Taganka, de Moscou, encenou Marat Sade sob a direção de Yuri Ljubimov no Teatro Vascello, em Roma. O Vascello, um teatro pequeno, estava lotado. No palco, o cenário parecia uma jaula de leão em um zoológico. 
Enquanto as barras haviam sido utilizadas na famosa produção de Peter Brook como um meio pelo qual os atores podiam instigar o público e ressaltar a relação dentro/fora, típica do teatro tradicional, no caso do Teatro Taganka aquelas mesmas barras forneciam um aparato circense no qual se podia balançar, andar na corda bamba, fazer acrobacias. Essa produção do Vascello não vinha acompanhada de legendas; o texto era uma tradução russa de uma peça de Peter Weiss. Uma parte do texto havia sido musicada, e quatro atores (vestidos como presidiários) tocavam instrumentos.

Quando a mesma produção foi apresentada no Festival de Avignon em 2000, havia legendas em francês acima do palco, montado em um pátio, ao ar livre. Foi uma experiência estranha ver aqueles atores extraordinariamente comunicativos, cujas vozes e corpos produziam significado da mesma forma que qualquer língua, sendo repentinamente separados pelas falas que diziam. Se o grupo em Roma parecia executar um espetáculo intrincadamente tecido, a presença das legendas, que atribuíam um texto específico a cada falante, fez subitamente a apresentação parecer mais uma peça do que uma dança/ópera. Conheço a peça; acho que minha reação teve menos a ver com o fato de não conhecer a história da primeira vez do que com a percepção de que a "ajuda" para a compreensão teve um estranho efeito redutor nesse caso. (Descarto deliberadamente as outras possibilidades óbvias — a mudança do local do evento, o público mais numeroso, o cenário do Festival.)

Essa relação preliminar de exemplos indica as consequências fenomenológicas das legendas em um evento performático, para usar o termo de Wilmar Sauter (Sauter, 2000). Vou apresentar agora meu último exemplo, extraído do RomaEuropa Festival de 2001, que sugere um novo nível de conscientização e brinca com o uso de legendas tradutórias.

Nas duas últimas décadas, os mecanismos da tradução simultânea foram incorporados às convenções teatrais do século XX: fingimos que a caixa com as palavras não está lá. ${ }^{4}$ No entanto, ao se entrar no Teatro Argentina para a apresentação de Endstation Amerika da companhia Volksbühne, de Berlim, via-se uma caixa retangular, fina e enorme (com o comprimento duas vezes maior do que as caixas de legendagem usuais) presa a correntes penduradas uns metros abaixo do normal, que não ficavam escondidas pela cortina, mas esticadas livremente no espaço da encenação. No momento em os espectadores viam a caixa de tradução, percebíamos que não se tratava

\footnotetext{
4 Outra forma de tradução menos comum, a qual não estou abordando neste artigo, é a tradução simultânea com fones de ouvido para as pessoas da plateia que desejarem utilizá-los.
} 
de uma ajuda discreta à compreensão, mas de uma representação textual na boca de cena.

Adaptação de Um bonde chamado desejo, de Tennessee Williams, Endstation Amerika foi apresentada em alemão com legendas em inglês e italiano. Como qualquer tradutor sabe, dizer simplesmente que se trata de uma tradução "do inglês" obscurece as inúmeras variantes desse idioma. As peças de Tennessee Williams foram escritas em um rico dialeto lírico sulista, de certa forma o dialeto norte-americano mais compatível com o italiano, uma vez que a pronúncia é lenta e carregada. Pode-se imaginar Blanche dizendo Good moore-ning parecido com o alongado Buon giooorno.

A adaptação do Volksbühne cortou a cena de abertura de Williams com uma "mulher negra"; na verdade a produção suprimiu da peça qualquer contexto afroamericano ou crioulo de Nova Orleans e concentrou as tensões raciais nos problemas entre os países da antiga Europa Oriental - o polonês Stanley passou a ser um exmembro do Partido da Solidariedade de Lech Walesa - e o Ocidente. Uma das maiores mudanças no cenário feitas pelo Volksbühne foi situar toda a peça em um quarto com um banheiro, no qual havia uma câmera de vídeo projetando o que acontecia lá dentro em uma tela de TV no quarto. Enquanto Um bonde chamado desejo (1949) de Williams incorporava a parte externa da casa, as sacadas, os degraus da entrada, a música das casas de blues que havia na mesma rua, Endstation Amerika encerra os personagens na caixa claustrofóbica composta de apartamento conjugado, aparelho de televisão, cama, banheiro e nenhuma vida na rua.

Assim, a caixa da legenda funciona no cenário como mais um elemento tecnológico, ignorado pelo elenco durante a maior parte da peça, mas presente de forma ostensiva na montagem para os espectadores. Algumas vezes, as próprias descrições de Williams em inglês para determinada cena apareciam na caixa antes da cena ocorrer. Essas citações do texto criavam uma dissonância, pois descreviam um tempo e lugar que quase sempre não se relacionavam com a encenação que estávamos vendo. "É cedo na manhã seguinte. Há uma confusão de gritos na rua que parece um canto coral" (Williams, 1959, p. 156). Essa indicação é traduzida para o italiano, sem o lirismo da expressão "canto coral”. Enquanto isso, os espectadores não escutam gritos na rua, pois os atores entram por uma porta que é a única entrada para o palco, e os espectadores não veem nada atrás dela a não ser escuridão.

Perto do final da encenação, quando Stanley já revelou o passado nem-um-poucobeldade-sulista de Blanche, sua vergonha é espalhada muito além das fofocas locais de 
um "operário" ou de um "comerciante" que vivera na cidade onde ela havia perdido o emprego de professora por ter tido um caso com um jovem de dezessete anos. Todos os membros do elenco, menos Blanche, vão para o canto do palco e olham para o alto para ver a "prova" da culpa de Blanche escrita na caixa. Como se recebessem as notícias dos letreiros luminosos de Times Square, os personagens liam "esta mulher não tem qualificação moral para o cargo que ocupa", "Hotel Flamingo", "jovem de dezessete anos". As palavras a princípio iam passando na forma convencional da legenda, depois começavam a piscar como um anúncio ou propaganda.

Colocar a legenda como parte da encenação é de fato quebrar esse tipo particular de quarta parede linguística, a que nos faz fingir que não estamos lendo, a que nos permite adequar nossa compreensão à ação que ocorre no palco, participando da intenção, como se fôssemos contrarregras fazendo a nossa parte, que é a de arrumar e rearrumar o cenário em nossas mentes. As iniciativas do Volksbühne sugerem, em minha opinião, que a incorporação da legenda eletrônica em espetáculos atingiu sua maioridade no teatro, o que é um convite para que surjam reflexões acerca desse processo. Muitas companhias europeias estão trabalhando intencionalmente com mais de uma língua, os atores nas companhias com frequência falam várias línguas, e as encenações cruzam fronteiras em uma Europa que pode ser unida pela mesma moeda, mas não por uma língua comum.

Em vez de direcionar o público para uma pretensa compreensão unificada, as companhias às vezes optam por tornar a língua novamente estranha. Essas experimentações são realizadas na maioria das vezes por companhias que criam espetáculos combinando texto, dança e música, em vez de trabalhar com uma peça convencional. Na mistura de gestos, mímica e música, o processo de demonstrar uma confusão linguística pode ser isolado em uma parte da encenação em que as palavras possam ser repetidas em três línguas diferentes, pressupondo-se que o público irá transcender o significado ao ouvir uma palavra que compreendem cercada por outras não familiares: aqua, water, wasser. Embora seja tentador especular de que forma, mesmo inconscientemente, um espectador poderá começar a "ver" a conexão entre as raízes das palavras nas línguas - pensemos em aqua, agua, eau - menciono essas ocasiões apenas para reiterar a reciprocidade crescente entre tradução como uma operação realizada e a encenação do próprio processo de recepção e retenção linguística em uma montagem. 
Endstation Amerika demonstra essa reciprocidade crescente que ocorre entre a tradução do texto original (realizada de forma tradicional ou não) e a ação no palco. No teatro, diretores e atores vêm há muito tempo experimentando lacunas, pausas, expressões idiomáticas intraduzíveis e rubricas não encenadas como parte da força do espetáculo ao vivo. Com o acréscimo das legendas, uma nova proeminência pode ser dada ao "não textual"; o paradoxo é que essa proeminência acontece exatamente devido à inserção do texto visual. Quando as legendas deixam de ser apenas uma ajuda à compreensão, elas se tornam parte da encenação. Adotada por um grupo como o Volksbühne, cuja reputação é a de uma companhia experimental, a legenda na mise-emscène ao mesmo tempo atingiu sua maioridade teatral e iniciou uma segunda adolescência de loquacidade idiossincrática e dramática exigência de atenção.

Artigo publicado originalmente em inglês, com o título "Watching in Translation: Performance and the Reception of Surtitles”, em Performance Research 7 (2) p. 26-30 Ltd. 2002. Tradução de Anna Olga Prudente de Oliveira, com revisão de Maria Paula Frota e Marcia A. P. Martins.

\section{Referências Bibliográficas:}

POOLE, Jane L. Use of Surtitles by Major Companies. Opera News, 14 fev 1987.

SAUTER, Wilmar. The Theatrical Event. Iowa: University of Iowa Press, 2000.

SHAKESPEARE, William. Re Lear. Trad. G. Melchiori. Turim: Oscar Classici Mondadori, 1976.

SISK, Douglas F. Surtitles ... Surtitles... Theatre Crafts 20:50, 1986.

WILliAMS, Tennessee. A Street Car Named Desire and Other Plays. London: Penguin Books, 1959. 